\title{
Pelayanan Penyuluh Pertanian Dan Kepuasan Petani Program System Rice Of Intensification (SRI) di Kabupaten Serdang Bedagai
}

\author{
Rahmad Syukur Siregar ${ }^{1 *}$ \\ Ade Firmansyah Tanjung ${ }^{2}$ \\ Salsabila ${ }^{3}$ \\ Aflahun Fadhly Siregar ${ }^{4}$ \\ Nana Trisna Kabaekan ${ }^{5}$ \\ Fadhly Akbar Lubis 6 \\ 1,2,3,4,5Universitas Muhammadiyah Sumatera Utara, Medan, Indonesia \\ ${ }^{6}$ Sekolah Tinggi Ilmu Pertanian Agrobisnis Perkebunan², Medan, Indonesia \\ *email:rahmadsyukur@umsu.ac.id \\ Diterima: November 2020; Disetujui: Maret 2021; Dipublish: April 2021
}

\begin{abstract}
Abstrak
Penyuluh pertanian sebagai ujung tombak dalam meningkatkan jumlah luas lahan persawahan yang menerapkan sistem budidaya System Rice Of Intensification (SRI) perlu diteliti pelayanannya. Sistem budidaya SRI sangat besar potensinya dalam meningkatkan kesejahteraan petani, karena terjadinya peningkatan produksi. Keadaan yang ada ternyata berbading terbalik dengan luas lahan petani yang menerapkan program SRI di Kabupaten Serdang Bedagai. Tujuan penelitian ini dilakukan adalah untuk mengetahui pengaruh kehandalan penyuluh secara parsial berpengaruh terhadap kepuasan petani, untuk mengetahui pengaruh perhatian penyuluh secara parsial berpengaruh terhadap kepuasan petani, untuk mengetahui kehandalan penyuluh memoderasi pengaruh perhatian terhadap kepuasan petani. Lokasi penelitian dilakukan pada tujuh kecamatan Serbajadi, Pantai Cermin, Teluk Mengkudu, Pengejahan, Perbaungan, Dolok Marsihul dan Bandar Khalifah di Kabupaten Serdang Bedagai. Metode sampling dilakukan dengan random sampling dan penentuan sampel dilakukan dengan mengunakan rumus Slovin, sehingga diperoleh jumlah sampel 77 responden dari 327 populasi. Metode analisis data dengan mengunakan analisis Structural Equation Modelling using Partial Least Square (SEM-PLS). Hasil penelitian menunjukkan bahwa:Kehandalan berpengaruh positif dan signifikan terhadap kepuasan petani program budidaya SRI di Kabupaten Serdang Bedagai, perhatian berpengaruh positif dan signifikan terhadap kepuasan petani program budidaya SRI dan kehandalan memberikan pengaruh yang lemah ketika memoderasi perhatian penyuluh terhadap kepuasan petani program budidaya SRI.
\end{abstract}

Kata Kunci: Kehandalan, Perhatian, System Rice Of Intesification, Kepuasan

\begin{abstract}
Agricultural extension officers are the spearhead in increasing the number of rice fields that apply the SRI cultivation system that need to be researched. The SRI cultivation system has a very large potential in improving the welfare of farmers due to able to increase production. In the fact, this situation is contrary to the land area of the farmers who implemented the SRI program in Serdang Bedagai District. The purposes of this research were to know the effect of agricultural extension officers reliability which partially affects farmer satisfaction in the Rice Of Intensification (SRI) cultivation program, to know the effect attention of agricultural extension officers partially on the satisfaction of farmers in the SRI cultivation program, to know agricultural extension officers reliability to moderate the effect of attention to farmer satisfaction of the SRI cultivation program. Research was carried out in seven subdistricts; Serbajadi, Pantai Cermin, Teluk Mengkudu, Pengejahan, Perbaungan, Dolok Marsihul and Bandar Khalifah in Serdang Bedagai District. The
\end{abstract}


method of determining the sample was carried out using the Slovin Formula so that 77 respondents were obtained from 327 respondents. Data were analyzed by Structural Equation Modeling analysis using Partial Least Square (SEM-PLS). The results showed that reliability had positive and significant effect on the satisfaction of farmers in the SRI cultivation program in Serdang Bedagai District, attention had positive and significant effect on farmer satisfaction in the SRI cultivation program and reliability had a weak effect when moderating the attention of agricultural extension officers to the satisfaction of SRI cultivation program farmers

Keywords: Reliability, Attention, System Rice Of Intesification, Satisfaction

\section{PENDAHULUAN}

Pertumbuhan pertanian di Indonesia memiliki peranan yang sangat penting dalam pembangunan ekonomi(Fayçal \& Ali, 2016). Sejarah menunjukkan bahwa pembangunan pertanian merupakan prasyarat untuk adanya kemajuan dalam tahapan-tahapan pembangunan selanjutnya.Pertanian memiliki keterkaitan dengan berbagai aspek dalam perekonomian, maka pembangunan pertanian merupakan penentu utama dalam pertumbuhan ekonomi pedesaan, termasuk di dalamnya non-pertanian di pedesaan (Eberhardt \& Vollrath, 2018). Pembangunan pertanian adalah tahapan yang esensial bagi upaya-upaya pengurangan kemiskinan di pedesaan maupun di perkotaan. Indonesia sebagai negara agraris tidak boleh meninggalkan potensi pertaniannya, tetapi dengan merubah pola pikir primitive menjadi modern melalui pendidikan dan kebijakan pemerintah, maka posisi pertanian dapat memberikan peran penting dalam pertumbuhan ekonominya.

Metode budidaya padi System Rice of Intesification (SRI) adalah sebuah metode baru tanaman padi yang dapat meningkatkan produktifitas lahan, mengurangi biaya penggunaan pupuk, mengurangi biaya tenaga kerja dan meningkatkan pendapatan (Ndiiri et al., 2013). Hal ini sebagai peluang untuk meningkatkan ketersedian pangan diberbagai daerah. Kabupaten Serdang Bedagai adalah kabupaten terluas yang memiliki lahan program budidaya SRI di provinsi sumatera utara (Pertanian, 2018) serta didukung tingginya intesitas penyuluhan pertanian tentang budidaya SRI.

Penyediaan beras sebagai pangan utama seharusnya dilakukan dengan peningkatan produktifitas lahan dalam negeri melalui metode budidaya tanaman padi. Kenyataanya produksi beras dalam negeri mengalami penurunan yang diakibatkan oleh adanya alih fungsi lahan pertanian (BPS, n.d.). Informasi dari petani SRI di kabupaten Serdang Bedagai diketahui bahwa telah banyak petani melakukan pengalihan pola tanam budidaya SRI kepola tanam budidaya konvensional. Hal ini sangat kontradiktif dengan potensi sistem budidaya SRI yang dapat meningkatkan kesejahteraan petani karena terjadinya peningkatan produksi.

Penelitian ini merupakan penelitian lanjutan dari hasil penelitian terdahulu yang dilakukan oleh peneliti. Penelitian terdahulu yang dilakukan oleh peneliti di tahun 2016 diketahui bahwa secara 
parsial variabel persepsi petani yang memberikan pengaruh signifikan terhadap kepuasan petani program SRI adalah variabel kehandalan dan perhatian (Muhammadiyah \& Utara, 2018). Hasil penelitian terdahulu masih belum menggambarkan implikasi yang optimal dalam ketepatan prediksi, sehingga peneliti berniat untuk melanjutkan penelitian pada bidang ini dengan metode analisis yang berbeda agar dapat menyempurnakan hasil penelitian yang lebih valid dalam mengukur kepuasan terhadap petani program SRI.

\section{METODE PENELITIAN}

Lokasi penelitian ini dilakukan dengan menggunakan metode purposive di Kab. Serdang Bedagai. Adapun alasan pemilihan lokasi ini adalah berdasarkan data yang telah dimiliki menjelaskan bahwa Kab. Serdang bedagai adalah kabupaten yang memiliki luas lahan program SRI di Provinsi Sumatera Utara terluas, dengan jumlah luas lahan 2180 Ha dalam 4 tahun terakhir (2013-2018) yang bersumber dari Dinas Pertanian Provinsi Sumatera Utara.

$\begin{array}{ccr}\text { Metode } & \text { sampling } & \begin{array}{r}\text { adalah } \\ \text { mengunakan } \\ \text { random }\end{array}\end{array}$ Penentuan jumlah sample menggunakan rumus slovin [4]. Populasi berjumlah 327 petani yang menerapkan metode budidaya SRI. Sampel ditetapkan 5\% dari jumlah populasi sehingga diperoleh angka 77 responden. Penentuan jumlah sampel dilakukan karena kondisi dilapangan yang bersifat homogen dengan indikator luas lahannya dan persepsi petani terhadap pelayanan penyuluh pertanian.

Metode Analisis dilakukan dengan Structural equation modeling (SEM) dengan pendekatan Part Least Square (PLS). Metode ini melakukan beberapa pengujian, yaitu : 1 . model pengukuran atau outler model (validitas konvergent dan validitas konstruk), 2 . model struktural atau inner model (besarnya pengaruh dari variabel laten eksogen terhadap variabel laten endogen), 3. koefisien determinasi (kemampuan model atau kemampuan variabel independen dalam menjelaskan variansi data pada variabel depeden. Nilai RSquare $0.75,0.50$ dan 0.25 dapat disimpulkan bahwa model kuat, moderate dan lemah (Hulland, 1999)), 4. Effectsize (efek moderasi) menunjukkan interaksi antara variabelindependen dengan variabel moderating dalam mempengaruhi variabel dependen. Efek moderasi yaitu dengan melihat nilai effectsize (f 2 ) yaitu $0.02,0.15$ dan 0,35 ini menunjukkan bahwa model lemah, moderate dan kuat. Effectsize untuk model moderating dapat dihitung dengan menggukan rumus:

$$
f^{2}=\frac{R^{2} \text { ModelModerasi }-R^{2} \text { ModelTanpaModerasi }}{1-R^{2} \text { ModelModerasi }}
$$

Jika effectsize yang dihasilkan lemah maka tidak akan berpengaruh terhadap efek interaksi. Mengetahui effectsize dari masing - masing variabel eksogen akan memudahkan kita mengetahui tingkat kepentingan 
perhatian variabel yang membentuk variabel endogen penelitian (Hair et al., 2017). Pada uji ini juga dilakukan uji arah pengaruh variabel.

\section{HASIL DAN PEMBAHASAN}

Model Pengukuran atau outler model
Evaluasi model pengukuran pada verifikasi indikator dan variabel laten adalah hal mutlak yang harus dilakukan sebelum dilakukan pengujian hipotesis. Hasil pengujian yang dilakukan dapat dilihat pada Gambar 1.

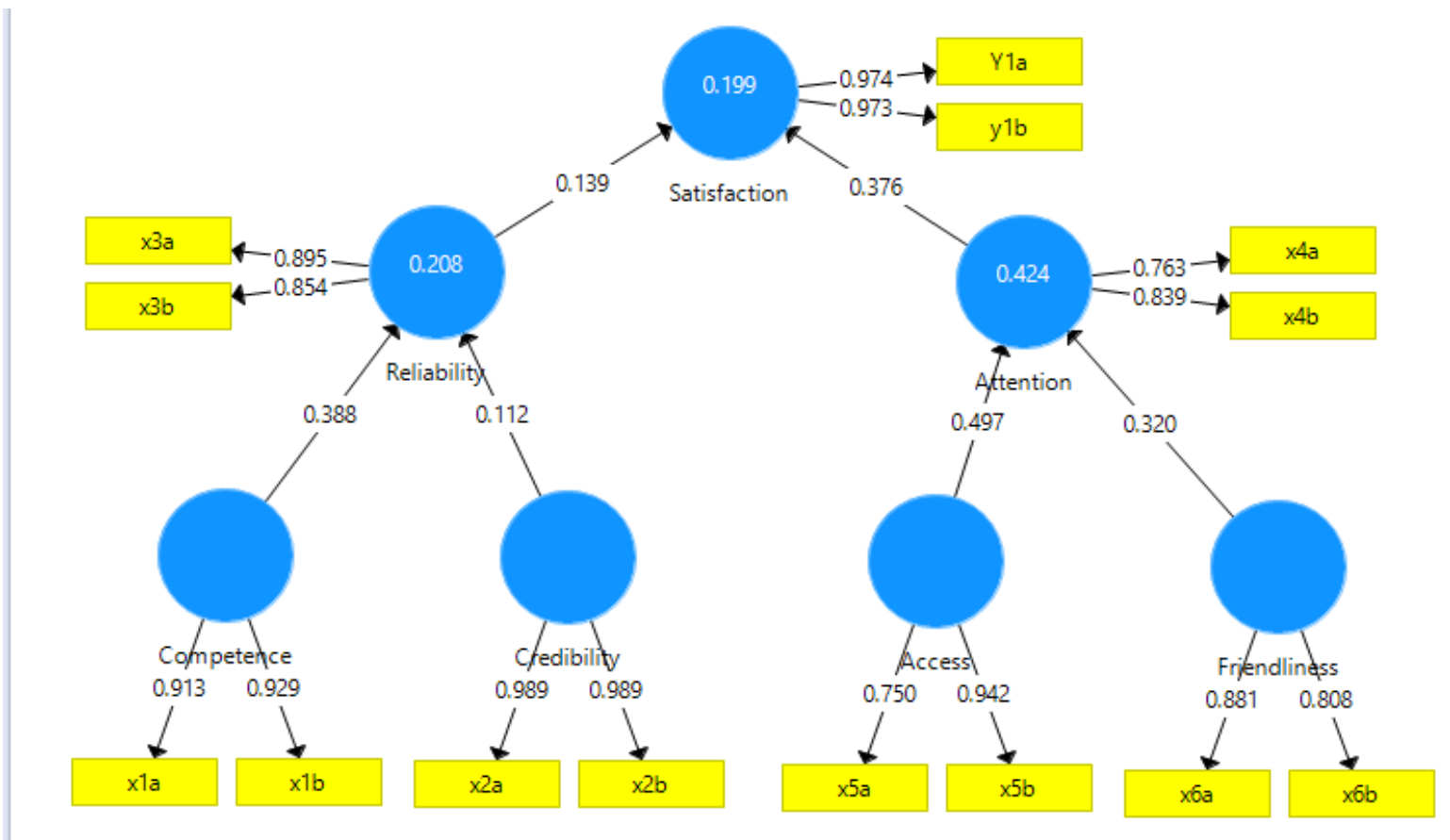

Gambar 1 Nilai Factor Loading dengan Diagram Jalur PLS

Berdasarkan Gambar 1 dapat diketahui bahwa lebih dari 90\% dari varian masing-masing pada kedua indikator, yaitu X1a dan X1b dapat dijelaskan oleh variabel laten kompetensi. Variabel laten kredibilitas dapat menjelaskan varian dari indikator $\mathrm{X} 2 \mathrm{a}$ dan $\mathrm{X} 2 \mathrm{~b}$ masing-masing lebih dari 90\%. Varian dari X3a dan X3b masingmasing dapat dijelaskan oleh variabel laten kehandalan di atas $80 \%$. Variabel akses mampu menjelaskan varian dari X5a dan X5b masing-masing lebih dari 70\%. Varian dari X6a dan X6b masingmasing dapat dijelaskan oleh variabel laten keramahan di atas 80\%.Variabel perhatian mampu menjelaskan varian dari X4a dan X4b masing-masing lebih dari 70\%. Sedangkan variabel laten derajat kepuasan sebagai variabel laten endogen mampu menjelaskan kedua indikatornya, yakni Y1a dan Y1b masingmasing di atas 90\%. Sehingga, secara keseluruhan masing-masing variabel laten telah mampu menjelaskan varian dari setiap indikator-indikator yang mengukurnya di atas 60\%. Kriteria selanjutnya yaitu composite reliability dan convergent validity (AVE) yang disajikan pada tabel 3 . 
Tabel 3. Composite Reliability dan AVE

\begin{tabular}{llcr}
\hline Variabel & Dimensi & Composite Reliability & AVE \\
\hline Kehandalan & Kompetensi & 0,918 & 0,848 \\
& Kredibilitas & 0,989 & 0,978 \\
Perhatian & Akses & 0,839 & 0,726 \\
& Keramahan & 0,833 & 0,715 \\
Kepuasan & & 0,973 & 0,948 \\
\hline
\end{tabular}

Sumber : Data diolah, 2020

Berdasarkan nilai composite reliability yang disajikan, diketahui bahwa ketujuh variabel laten memiliki nilai composite reliability dan nilai AVE di atas 0,5. Artinya, indikator yang telah ditetapkan telah mampu mengukur setiap variabel laten (konvergent) dengan baik atau dapat dikatakan bahwa ketujuh model pengukuran telah reliabel. Nilai convergent validity yang semakin baik ditunjukkan dengan semakin tingginya korelasi antar indikator yang menyusun suatu konstruk. Uji validitas diskriminan dinilai berdasarkan nilai cross loading dengan konstruknya. Suatu indikator dinyatakan valid atau telah memenuhi validitas diskriminan jika mempunyai nilai tertinggi kepada konstruk yang dituju dibanding nilai kepada konstruk lain. Hal ini dapat dilihat bahwa setiap indikator memiliki nilai cross loading tertinggi ketika dihubungkan dengan konstruk yang dituju dibandingkan ketika dihubungkan dengan konstruk yang lain. Seperti, nilai cross loading untuk indikator kompetensi (X1a sampai X1b) mempunyai nilai cross loading kepada konstruk kompetensi lebih besar dari yang lainnya.

Tabel 4. Nilai Cross Loading

\begin{tabular}{lrrrrrrr}
\hline & $\begin{array}{c}\text { Kompeten } \\
\text { si }\end{array}$ & $\begin{array}{c}\text { Kredibilita } \\
\text { s }\end{array}$ & $\begin{array}{c}\text { Kehandal } \\
\text { an }\end{array}$ & Akses & $\begin{array}{c}\text { Keramah } \\
\text { an }\end{array}$ & $\begin{array}{c}\text { Perhati } \\
\text { an }\end{array}$ & $\begin{array}{c}\text { Kepuas } \\
\text { an }\end{array}$ \\
\hline X1a & 0,913 & 0,358 & 0,388 & 0,186 & 0,463 & 0,428 & 0,304 \\
X1b & 0,929 & 0,569 & 0,43 & 0,196 & 0,421 & 0,462 & 0,391 \\
X2a & 0,518 & 0,989 & 0,309 & 0,324 & 0,314 & 0,754 & 0,466 \\
X2b & 0,487 & 0,989 & 0,304 & 0,294 & 0,329 & 0,763 & 0,449 \\
X3a & 0,382 & 0,272 & 0,895 & 0,071 & 0,574 & 0,321 & 0,318 \\
X3b & 0,4 & 0,271 & 0,854 & 0,203 & 0,808 & 0,326 & 0,155 \\
X5a & 0,196 & 0,132 & 0,055 & 0,75 & 0,165 & 0,305 & 0,173 \\
X5b & 0,175 & 0,347 & 0,171 & 0,942 & 0,227 & 0,602 & 0,411 \\
X6a & 0,411 & 0,28 & 0,506 & 0,197 & 0,881 & 0,407 & 0,191 \\
X6b & 0,4 & 0,271 & 0,854 & 0,203 & 0,808 & 0,326 & 0,155 \\
X4a & 0,487 & 0,989 & 0,304 & 0,294 & 0,329 & 0,763 & 0,449 \\
X4b & 0,306 & 0,304 & 0,292 & 0,6 & 0,37 & 0,839 & 0,254 \\
Y1a & 0,391 & 0,49 & 0,286 & 0,352 & 0,204 & 0,406 & 0,973 \\
Y1b & 0,349 & 0,411 & 0,255 & 0,383 & 0,198 & 0,425 & 0,974 \\
\hline
\end{tabular}

Sumber : Data diolah, 2020 


\section{Model Struktural (Inner Model)}

Analisis inner model dilakukan dengan mengestimasi koefisien jalur hubungan antar konstruk. Nilai path coefficient pada hubungan antar variabel menjadi acuan dalam melakukan estimasi. Nilai positif mengindikasikan adanya pengaruh positif dan sebaliknya nilai negatif mengindikasikan adalah pengaruh negatif. Semakin besar nilai path coefficient, maka semakin besar pengaruh antar variabel tersebut.

a. Variabel Kehandalan

Variabel kehandalan disusun oleh dua dimensi yaitu kompetensi dan kredibilitas. Untuk mengetahui besarnya pengaruh atau kontribusi masing-masing dimensi terhadap variabel kehandalan dapat dilihat pada tabel berikut:

Tabel 6. Path Coefficients

\begin{tabular}{lrrr}
\hline & OriginalSample & T-Statistics & P Values \\
\hline Kompetensi $\rightarrow$ Kehandalan & 0,388 & 2,472 & 0,017 \\
Kredibilitas $\rightarrow$ Kehandalan & 0,112 & 0,886 & 0,353 \\
\hline
\end{tabular}

Sumber : Data diolah, 2020

Dimensi kompetensi memberikan kontribusi pengaruh sebesar 0,388 terhadap variabel kehandalan dengan nilai Tstatistik sebesar 2,472 dan pvalues sebesar 0,017. Dimensi kredibilitas memberikan kontribusi pengaruh sebesar 0,112 terhadap kehandalan dengan nilai Tstatistik sebesar 0,886 dan p-values sebesar 0,353. Pada variabel kompetensi memberikan kontribusi pengaruh paling besar terhadap kehandalan dibandingkan dengan variabel kredibilitas.

b. Variabel Perhatian

Variabel perhatian disusun oleh duadimensiyaituakses dan keramahan. Untuk mengetahui besarnya pengaruh atau kontribusi masing-masing dimensi terhadap variabel perhatian dapat dilihat pada tabel berikut:

Tabel 7. Path Coefficients

\begin{tabular}{lrrrr}
\hline & & OriginalSample & T-Statistics & P Values \\
\hline Akses $\rightarrow$ & Perhatian & 0,497 & 5,339 & 0,000 \\
Keramahan $\rightarrow$ & Perhatian & 0,320 & 3,215 & 0,001 \\
\hline
\end{tabular}

Sumber : Data diolah, 2020

Dimensi akses memberikan kontribusi pengaruh sebesar 0,497 terhadap variabel perhatian dengan nilai Tstatistik sebesar 5,339 dan p-values sebesar 0,000. Dimensi keramahan memberikan kontribusi pengaruh sebesar 0,320 terhadap perhatian dengan nilai Tstatistik sebesar 3,215 dan p-values sebesar 0,001. Dalam penelitian ini, variabel akses memberikan kontribusi pengaruh paling besar terhadap perhatian dibandingkan dengan variabel keramahan. 
c. Pengaruh Langsung (DirectEffects)

Mengetahui bagaimana pengaruh

langsung variabel independen terhadap variabel dependen dapat dilihat dalam tabel berikut:

Tabel 8. Direct Effects

\begin{tabular}{lr}
\hline Pengaruh & Path Coefficients \\
\hline Kehandalan $\rightarrow$ Kepuasan & 0,139 \\
Perhatian $\rightarrow$ Kepuasan & 0,376 \\
\hline Sumber : Data diolah, 2020 &
\end{tabular}

Membentuk kepuasan petani, kehandalan dan perhatian memberikan dampak masing-masing secara langsung pengaruh positif. Besarnya pengaruh langsung kehadalan terhadap kepuasan petani adalah 0,139 dan besarnya pengaruh langsung perhatian terhadap kepuasan petani adalah 0,379. Besarnya pengaruh dari perhatian lebih besar dari pengaruh kehandalan $(0,376>0,139)$.

1. Uji Koefisien Determinasi (R2)

Koefisien Determinasi digunakan untuk melihat seberapa besar pengaruh variabel independen terhadap variabel dependen, semakin besar nilainya berarti semakin besar pengaruhnya. Oleh karena jumlah indikator setiap konstruk yang beragam jumlahnya, analisis koefisien determinasi dilakukan dengan melihat nilai pada adjusted R-square. Nilai adjusted Rsquare diperoleh dengan perhitungan algoritma Smart PLS dan dapat dilihat pada tabel berikut.

Tabel 9. Koefisien Determinasi

\begin{tabular}{lrr}
\hline Hubungan & R Square & \multicolumn{2}{c}{ R SquareAdjusted } \\
\hline Kehandalan, Perhatian $\rightarrow$ Kepuasan & 0,199 & 0,177 \\
Sumber : Data diolah, 2020 & &
\end{tabular}

Pengaruh dari kehandalan dan perhatian secara bersama-sama dalam membentuk kepuasan petani adalah sebesar $17,7 \%$. Sisanya, sebanyak $82,3 \%$ dijelaskan oleh variabel lain di luar penelitian.

2. EffectSize (F2)

Pengevaluasian model struktural (inner model) dengan menggunakan effectsize $\left(f^{2}\right)$ digunakan untuk melihat besarnya pengaruh masing-masing variabel laten eksogen dalam membentuk variabel endogen. Effectsize mengukur kontribusi antar variabel terhadap bentukan R2. Nilai dari $f^{2}$ ini menentukan besarnya pengaruh dari masing-masing variabel. Acuan nilai yang digunakan adalah 0.02 mengindikasikan pengaruh lemah, 0.15 mengindikasikan sedang dan 0.35 mengindikasikan kuat. Berdasarkan hasil perhitungan effect size $f^{2}$ yaitu 0,104, jika terbukti signifikan maka variabel kehandalan sebagai variabel moderating memberikan efek sedang pada variabel perhatian terhadap kepuasan petani pada penelitian ini.

Pengujian hipotesis penelitian dilakukan dengan cara melihat hasil nilai 
dari t-statistik inner model yang telah dibentuk. Apabila nilai t-statistik >t-tabel yaitu1,64(hipotesis dua arah) dan nilai tstatistik <t-tabel yaitu1,64 (hipotesis satu arah) maka hubungan antar konstruk dapat dikatakan tidak signifikan pada $\alpha=5 \%$.

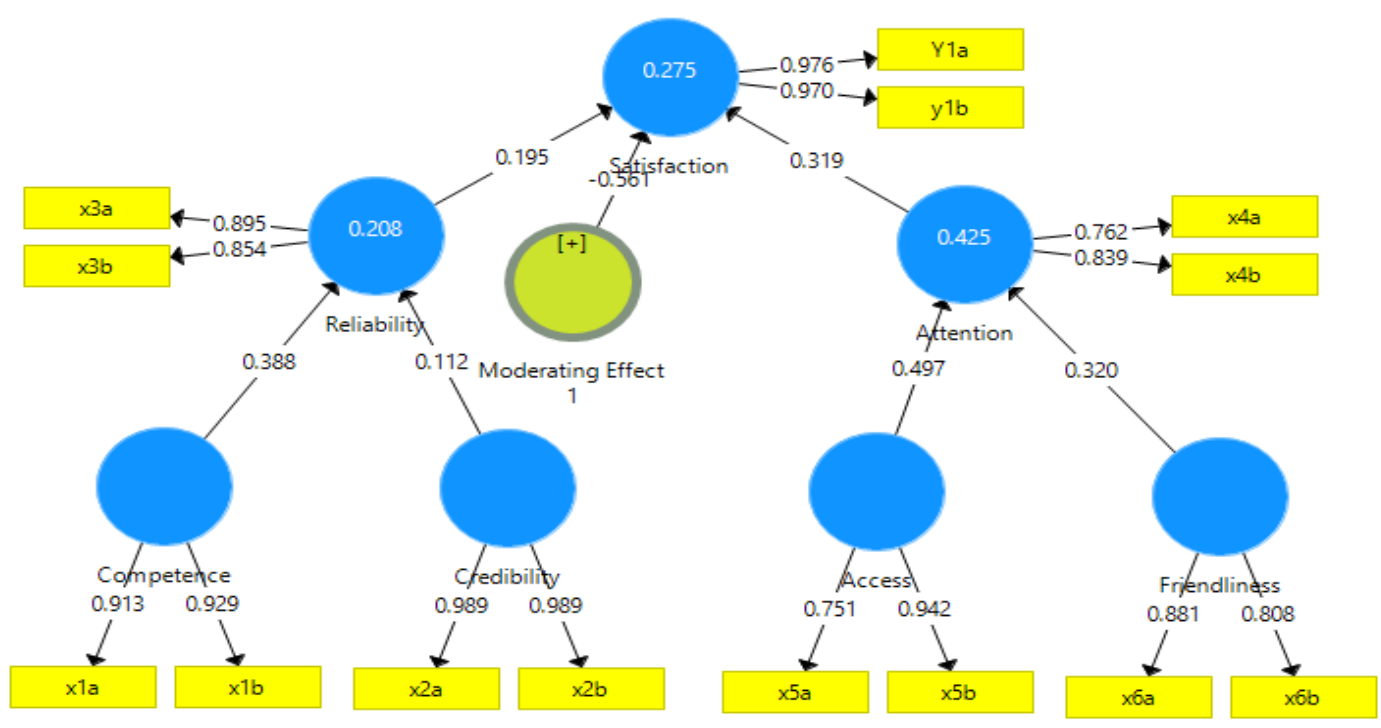

Gambar 2 Hasil Bootstrap Model Variabel Laten

Gambar 2 menunjukkan bahwa pengaruh masing-masing variabel adalah positif dan ada yang signifikan serta tidak signifikan. Terdapat tiga hipotesis yang akan dijawab dalam penelitian ini dan hasil dari pengujian hipotesis dapat dilihat pada tabel dibawah menyimpulkan bahwa dua hipotesis diterima dimana nilai $t$ statistik lebih besar daripada nilai $\mathrm{t}$ tabel dan satu hipotesis ditolak karena lebih kecil nilai t-statistiknya dari nilai t-tabel dengan tingkat signifikansi $\alpha=$ $5 \%$.

Tabel 10. Pengujian Hipotesis

\begin{tabular}{llrrrl}
\hline Hipotesis & & Originalsample & t-stat & p-value & Kesimpulan \\
\hline Kehandalan $\rightarrow$ Kepuasan & 0,195 & 1,691 & 0,091 & Diterima \\
Perhatian $\rightarrow$ Kepuasan & 0,319 & 2,885 & 0,004 & Diterima \\
Moderate $\rightarrow$ Kepuasan & 0,561 & 1,638 & 0,102 & Ditolak \\
\hline
\end{tabular}

Sumber : Data diolah, 2020

Jadi, ketiga hipotesis dibawah ini sudah terjawab dengan melihat Tabel 10 untuk hasil pengolahan datanya yaitu: faktor-faktor kehandalan penyuluh berpengaruh positif dan signifikan terhadap kepuasan petani $\rightarrow$ DITERIMA.
Faktor-faktor perhatian berpengaruh positif dan signifkan terhadap kepuasan petani $\rightarrow$ DITERIMA. Kehandalan memoderasi pengaruh faktor-faktor perhatian terhadap kepuasan petani $\rightarrow$ DITOLAK. 
Variabel kehandalan penyuluh berpengaruh positif dan signifikan terhadap kepuasan $\rightarrow$ DITERIMA . Dimana nilai t-statistik lebih besar dari ttabel yaitu 1,691. Fenomena dilapangan menjelaskan bahwa intensitas kunjungan yang dilakukan penyuluh dalam memberikan arahan sesuai waktu yang dijanjikan dan periode kunjungan yang dilakukan penyuluh terhadap wilayah kerjanya dilakukan secara berkala yaitu 2-3 kali seminggu. Dimana pada pemberian pelayanan pertama oleh penyuluh tidak mengalami kendala atau kesalahan yang dilakukan oleh penyuluh itu sendiri. Seperti pada saat petani mempertanyakan kondisi air yang tepat pada saat pagi, siang dan sore hari dan penyuluh menyebarkan kontak personnya pada petani agar memudahkan dalam menanyakan kendala yang dialami petani. Hasil penelitian ini sesuai dengan penelitian Listiana (2018), Berkat dan Sunaryati (2015), Mujiburrahmad dkk (2018) bahwa kualitas kehandalan penyuluh dapat memuaskan petani jika adanya upaya penyuluh yang dapat memenuhi kebutuhan petani seperti pengadaan traktor dan membantu penyusunan laporan dan proposal petani.

Variabel perhatian berpengaruh positif dan signifkan terhadap kepuasan petani $\rightarrow$ DITERIMA. Dimana nilai $t-$ statistik lebih besar dari t-tabel yaitu 2,885 . Fenomena yang terjadi dilapangan menjelaskan bahwa sikap penyuluh dalam melakukan penyuluhan sangat meyakinkan dilihat dari kualitas perhatian yang diberikan, seperti penyuluh selalu membawa catatan penyuluh tentang petani yang sedang dalam penyuluhan dan mencatat perkembangan tanaman padi petani. Penyuluh juga memberikan motivasi terhadap petani dan memberikan solusi bagi petani yang mengalami kesulitan dalam pengolahan tanah, seperti ikut membantu pembuatan-pengajuan proposal petani yang membutuhkan handtraktor dan ikut mempraktekkan jumlah bibit per lubang dan posisi akar pada waktu tanam. Hal ini sesuai dengan penelitian Elias et al., (2016) dan Ganpat et al., (2014) bahwa semakin banyak informasi (perhatian) yang diberikan penyuluh pertanian kepada petani maka berpengaruh secara signifikan terhadap kepuasan petani. Informasi yang diberikan penyuluh pertanian memberikan peluang lebih banyak mendapatkan pendapatan yang lebih tinggi dan meningkatkan kepercayaan terhadap penyuluh pertanian (Nona et al., 2020). Sofee dan Ngulube (2016) dalam penelitiannya mengatakan bahwa akses informasi yang tinggi akan mengakibatkan peningkatan produktifitas petani dan mengurangi peluang petani untuk mengalami kerugian.

Variabel kehandalan sebagai variabel moderasi memiliki nilai $t$ statistik sebesar 1,638 dengan nilai $p$ value sebesar 0,102 . Perolehan nilai tstatistik diatas lebih kecil dari nilai ttabel yang mengindikasikan memiliki pengaruh yang tidak signifikan. Akan tetapi variabel kehandalan bersifat signifikan sebagai variabel bebas bukan sebagai variabel moderasi. Kehandalan tidak akan memoderasi pengaruh faktor- 
faktor perhatian penyuluh terhadap kepuasan petani. Kehandalan berpengaruh secara langsung terhadap keputusan tersebut. Hasil penelitian ini sesuai dengan teori Rangkuti (2002) yang menyatakan bahwa untuk melihat kepuasan konsumen dalam dimensi kehandalan pelayanan hal ini dilihat dari pemberian pelayanan yang unggul seperti tidak melakukan kesalahan pada saat pertama kali memberikan pelayanan, tepat waktu sesuai yang dijanjikan dan selalu mengahasilkan kebijakan yang menciptakan keterikatan emosional dengan konsumennya.

\section{SIMPULAN}

Kehandalan penyuluh memiliki pengaruh positif dan signifikan terhadap kepuasan petani. Keseluruhan aspek yang terdapat dari variabel tersebut yang terdiri dari kompetensi dan kredibilitas memliki pengaruh yang positif signifkan terhadap kepuasan petani. Semakin baik dan jelas praktik dari kompetensi dan kredibilitas yang diberikan penyuluh kepada petani maka semakin tinggi tinggkat kepuasan petani. Perhatian memiliki pengaruh positif dan signifikan terhadap kepuasan petani. Semakin tinggi perhatian penyuluh terhadap petani semakin tinggi kepuasan petani. Kepuasan petani bersumber dari rasa perhatian penyuluh kepada petani. Penting untuk menata penyuluh dalam menumbuhkan rasa perhatian kepada petani. Kehandalan tidak memoderasi pengaruh antara variabel perhatian terhadap kepuasan petani. Kehandalan lebih bersifat sebagai variabel bebas yang mempengaruhi kepuasan petani. Kehandalan tidak akan menguatkan atau melemahkan pengaruh dari perhatian terhadap kepuasan petani melainkan memberikan pengaruhnya secara langsung pada kepuasan petani yang dilakukan oleh penyuluh.

\section{UCAPAN TERIMAKASIH}

Peneliti mengucapkan terima kasih kepada Rektor UMSU dan Ketua LP2M UMSU sebagai pihak yang telah memberikan dana untuk melaksanakan penelitian dengan skim penelitian dosen pemula. Penelitian dilakukan pada tahun 2017 dan dengan nomor kontrak 56/II.3AU/UMSU/-LP2M/F/2017.

\section{DAFTAR PUSTAKA}

Berkat dan Sunaryati, R. (2015). Analisis Kepuasan Petani Terhadap Kegiatan Penyuluhan Pertanian di Kelurahan Kalampangan, Kota Palangka Raya Kalimantan Tengah. Daun: Jurnal Ilmiah Pertanian Dan Kehutanan, 2(1), 45-53. https://doi.org/10.33084/daun.v2i 1.172

BPS. (n.d.). No Title. Produksi Padi Tahun 2014 (ARAM II) Diperkirakan Turun 0,94 \% Dari Tahun 2013. https://www.bps.go.id/pressreleas e/2014/11/03/232/produksi-paditahun-2014--aram-ii--diperkirakanturun-0-94--persen-dari-tahun2013.html

Duc, N. M. (2008). Farmers' satisfaction with aquaculture - A logistic model in Vietnam. Ecological Economics, 68(1-2), 525-531. https://doi.org/10.1016/j.ecolecon. 2008.05.009

Eberhardt, M., \& Vollrath, D. (2018). The Effect of Agricultural Technology on the Speed of Development. World Development, 109, 483-496. https://doi.org/10.1016/j.worldde v.2016.03.017 
Elias, A., Nohmi, M., Yasunobu, K., \& Ishida, A. (2016). Farmers' satisfaction with agricultural extension service and its influencing factors: A case study in north west Ethiopia. Journal of Agricultural Science and Technology, 18(1), 3953.

Fayçal, M., \& Ali, H. M. (2016). Economic Growth and Government Subventions for Agriculture Sector in Algeria: An ARDL Model. Arab Economic and Business Journal, 11(2), 105-114. https://doi.org/10.1016/j.aebj.201 6.10 .001

Ganpat, W. G., Webster, N., \& Narine, L. K. (2014). Farmers' satisfaction with extension services in the organization of Eastern Caribbean states. Journal of International Agricultural and Extension Education, 21(3), 49-62. https://doi.org/10.5191/jiaee.2014 .21304

Hair, J. F., Hult, G. T. M., Ringle, C. M., Sarstedt, \& M. (2017). A Primer on Partial Least Squares Structural Equation Modeling (PLS-SEM). 363. https://doi.org/10.1017/CB09781 107415324.004

Hulland, J. (1999). Use of partial least squares (PLS) in strategic management research: a review of four recent studies. Strategic Management Journal, 20(2), 195204.

https://doi.org/10.1002/(SICI)109

7-0266(199902)20:2<195::AIDSMJ13>3.3.CO;2-Z

Listiana, I., Sadono, D., \& Tjiptopranoto, P. (2018). Indah Listiana 1, Sumardjo 2 - Dwi Sadono 2, Prabowo Tjiptopranoto 2. 14(2).
Msoffe, G., \& Ngulube, P. (2016). Farmers' access to poultry management information in selected rural areas of Tanzania. Library and Information Science Research, 38(3), 265-271. https://doi.org/10.1016/j.lisr.2016 .08 .004

Muhammadiyah, U., \& Utara, S. (2018). pengaruh persepsi petani atas pelayanan penyuluh pertanian dan karakteristik petani terhadap kepuasanpetani program budidayasystem rice of intensification, October.

Mujiburrahmad, Baihaqi, A., \& Manyamsari, I. (2020). Analisis Pengaruh Kualitas Pelayanan Penyuluh Terhadap Kepuasan Petani dalam Pengembangan Usaha tAni di Kabupaten Pidie. Jurnal AGRISEP, 19(1), 83-98. https://doi.org/10.31186/jagrisep. 19.1.83-98

Ndiiri, J. A., Mati, B. M., Home, P. G., Odongo, B., \& Uphoff, N. (2013). Adoption , constraints and economic returns of paddy rice under the system of rice intensification in Mwea, Kenya. Agricultural Water Management, 129, 44-55. https://doi.org/10.1016/j.agwat.20 13.07.006

Nona, R. V., Ayu, I., \& Juniasih, K. (2020). Kabupaten Ende Provinsi Nusa Tenggara Timur. Litbang Pertanian, 151-162.

Pertanian, D. (2018). ( $R E N S T R A$ ) Dinas Pertanian Provinsi Sumatera Utara Periode 2013-2018. 6.

Rangkuti, F. (2002). Teknik Mengukur dan Strategi Meningkatkan Kepuasan Pelanggan dan Analisis Kasus PLN-JP. Gramedia Pustaka. 